\title{
How aggressive ant-guards assist seed-set in Acacia flowers
}

\section{P. G. Willmer \& G. N. Stone* \\ School of Biological \& Medical Science, University of St Andrews, Fife KY16 9TS, UK \\ * Department of Zoology, South Parks Road, Oxford OX1 3PS, UK}

The phenomenon of ant-guarding on Acacia trees is probably the best known case of a mutualism between plants and animals, the ants conferring biotic defence against herbivores and perhaps against encroaching vegetation ${ }^{1-3}$. However, as with many defence mutualisms, sometimes the interests of the plant and its defender conflict: for example, when they are in flower the Acacia trees require the presence and service of other insects to effect crosspollination. How is pollinator access achieved in the face of aggressive ant-guards? Here we report that ants are deterred from young flowers at the crucial stage of dehiscence, allowing bees and other pollinators to visit and transfer pollen. This deterrence appears to be a response to a volatile chemical signal from young flowers, perhaps from the pollen itself. Ants patrol the young (undehisced) buds, and also return to the flowers after dehiscence, protecting the fertilized ovules and developing seeds. The outcome is a directly improved seed-set in the presence of ants (rather than an indirect extra reproductive resource allocation due to decreased defoliation ${ }^{4-6}$ ).

Acacia zanzibarica and A. drepanolobium are classic ant-guarded trees of eastern Africa ${ }^{7}$; ants (such as Crematogaster ${ }^{8}$ ) reside on the trees inside modified thorns (pseudogalls) and patrol the branches, attacking any insect or vertebrate herbivores encountered. As in other guarded Acacias $^{1-3}$, herbivory is thereby much reduced. Crosspollination could be allowed through reduced ant activity during flowering but, as flowers appear soon after seasonal rains and accompany the flush of vegetative growth, this would leave the tree foliage and the flowers themselves vulnerable to damage.

A. zanzibarica and A. drepanolobium flowers occur in spherical inflorescences of 20-100 florets bearing conspicuous exposed anthers. Flowering occurs mainly in November-January in Mkomazi. The flowers open at around 05:00 and start to dehisce at 08:00-09:00 (ref. 9). They appear pristine through day 1, persisting through day 2 in a tattered non-functional state before being shed, leaving a small proportion of ovules effectively fertilized. Seed-set is apparent within 2-3 days, although seeds take about a month to mature.

Flower visitors operate on clear diurnal patterns ${ }^{9}$. As in other Acacias $^{10}$, most pollen collection is carried out by solitary bees (Megachilidae and Halictidae), making $98 \%$ of visits to A. drepanolobium and $40 \%$ of visits to $A$. zanzibarica. Bee activity begins from first dehiscence and peaks at 11:00-14:00 (ref. 9); around 75-80\% of available pollen is removed within these 3 hours. The flowers contain little or no nectar and, unlike some sympatric Acacia species, are therefore relatively unattractive to nectarivorous pollinators such as butterflies ${ }^{9}$. However, flower predation by beetles (melioids and scarabaeids) is a significant problem, with anthers, stigmas and ovaries being chewed in about $10 \%$ of flowers.

Ants also show a daily activity pattern (Table 1), patrolling twigs adjacent to their pseudogall in the early morning, declining in numbers from 09:00-10:00, only rarely in evidence until around 14:00, then increasing during most of the afternoon. Therefore, there are strictly defined times when ants are not present on flowers, corresponding to peak dehiscence and visitation of flowers. Because of the temporal patterning of their behaviours, pollinators meet

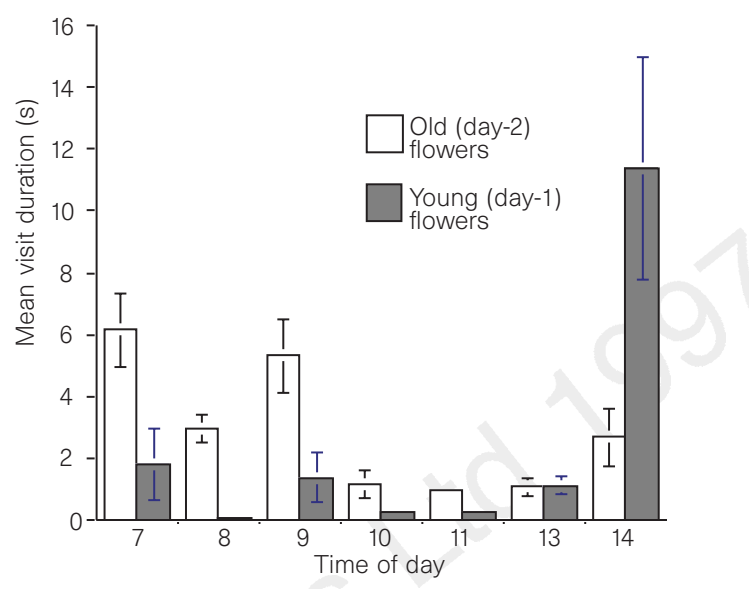

Figure 1 Duration of visits of young and old flowers of Acacia zanzibarica through the diurnal cycle, as mean values ( \pm s.e.m.) from 4 days of observation.

\begin{tabular}{|c|c|c|c|c|}
\hline \multirow[b]{2}{*}{ Time } & \multicolumn{3}{|c|}{ A. zanzibarica } & \multirow{2}{*}{$\frac{\text { A. drepanolobium }}{21 \mathrm{Dec}}$} \\
\hline & $22 \mathrm{Nov}$ & 24 Nov & $17 \mathrm{Dec}^{*}$ & \\
\hline 06:00-07:00 & - & - & 9.5 & - \\
\hline 07:00-08:00 & 6.7 & 13.7 & 7.2 & 19.2 \\
\hline 08:00-09:00 & 3.8 & 8.6 & 6.9 & 11.0 \\
\hline 09:00-10:00 & 1.8 & 4.7 & 5.9 & 5.4 \\
\hline 10:00-11:00 & 0.4 & 3.3 & 2.3 & 4.0 \\
\hline $11: 00-12: 00$ & 1.1 & 3.2 & 2.4 & 4.4 \\
\hline $12: 00-13: 00$ & 0.9 & 1.5 & 2.4 & 1.7 \\
\hline $13: 00-14: 00$ & 0.9 & 2.3 & 0.3 & 1.1 \\
\hline $13: 00-15: 00$ & 2.7 & 3.7 & 0.4 & 4.2 \\
\hline $15: 00-16: 00$ & 3.4 & 7.5 & 0.7 & 5.0 \\
\hline $16: 00-17: 00$ & 3.7 & - & 2.6 & 5.7 \\
\hline $17: 00-18: 00$ & 3.1 & 10.9 & 6.9 & 7.1 \\
\hline
\end{tabular}

The mean numbers of ants patrolling per 10 marked 0.5 -m lengths of branch of different Acacia trees on different days in 1995 .

* Trees not in flower.

\begin{tabular}{lrrrrc}
\hline \multicolumn{7}{l}{ Table 2 ANOVA for duration of ant visits } & & & \\
\hline Source & DF & Seq SS & Adj MS & $F$ & $P$ \\
Age & 1 & 43,917 & 1,999 & 0.20 & 0.652 \\
Time & 8 & 229,084 & 23,627 & 4.83 & 0.000 \\
Age $\times$ time & 8 & 128,042 & 16,005 & 3.27 & 0.001 \\
Error & 265 & $1,295,876$ & 4,890 & & \\
Total & 282 & $1,696,919$ & & &
\end{tabular}

The analysis of variance is shown for the duration of ant visits with age of flower and time. Seq SS, Sequential sum of squares; Adj MS, adjusted mean squares. DF, degrees of freedom.

relatively few ants on the flowers. Nevertheless, ants and pollinators such as bees do overlap in their flower-visiting activities, especially at the onset of dehiscence. How then is conflict avoided?

Ant activities in relation to flower age (Fig. 1) show that antflower interactions are more subtle than indicated by an assessment of mere presence or absence. In the early morning, the ants visit more of, and make longer visits to, older (day-2) flowers and the unopened buds (not shown), but significantly avoid younger flowers and stay only briefly (often for 1-5 seconds) when they do encounter a young flower. During such visits, they also differ in their behaviour, with their antennae and mandibles being unusually active and the abdomen often being cocked upwards. Ants could be reacting to flower occupancy by pollinators, but 'occupied' flowers are rare at these times (07:00-10:00) and ants make equally short visits to both occupied $(6.47 \pm 7.20 \mathrm{~s} ; n=11)$ and unoccupied (7.15 $\pm 5.45 \mathrm{~s} ; n=75)$ young flowers. In contrast, when ant activity increases again in the afternoon, younger flowers are intensively 


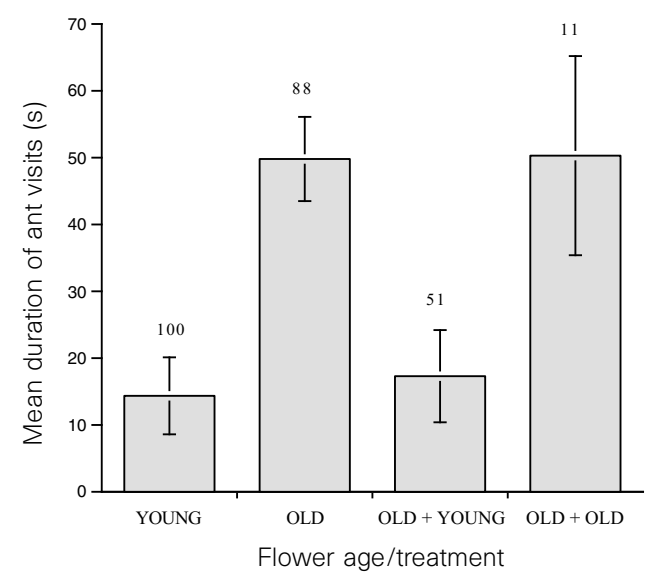

Figure 2 Duration of visits (mean \pm s.e.m.; $n$ above bars) between 07:00-09:30 from two days of observation with four age/treatment groups of $A$. zanzibarica flowers (see Methods).

visited and for significantly longer than during morning visits (Table 2: age, not significant; time, $P=0.000$; time/age interaction, $P=0.005)$. These patterns could be explained by young flowers producing a deterrent to ants when they first dehisce.

The changing response of ants to young flowers suggests that there is a progressive decay of ant-repellant stimulus after dehiscence. This could result from a short-lived volatile chemical signal from the young flowers. Some flowers do contain ant-repellant nectar ${ }^{11,12}$, but this is an implausible source of repellant in Acacia zanzibarica, where nectar volumes are negligible. The repellant must be present either on the corolla surfaces or on the pollen itself. It might therefore be transferable by contact between flowers, either by direct wiping of chemical(s) or by transfer of whole pollen grains/ polyads. To test this, we watched ant behaviour on selected $A$. zanzibarica trees, treated as described under Methods. Figure 2 shows that old flowers receive longer morning visits than young ones, as expected (Fig. 1); wiping old flowers with other old flowers has no effect, whereas wiping with young flowers produces avoidance and shorter visits, as for untreated young flowers (ANOVA, $F=17.63, P=0.000$ ), and also elicits an exaggerated behavioural response. Some component transferable from the young dehiscing flowers (therefore a chemical rather than a tactile cue) is acting as an ant deterrent. If freshly dehiscing flowers have a volatile antdeterrent, this also explains why just one day of observation (27 November 1995) gave ant-visit durations that were invariant between young ( $40 \pm 11 ; n=12)$ and old ( $34 \pm 6 \mathrm{~s} ; n=9)$ flowers; rain on that morning had presumably washed away the deterrent cue.

In this model, ants could aid Acacia pollination by keeping the very young flower buds pristine and uneaten, then by their absence allowing access to pollinators at peak flower fertility (with the small cost of losing some young flowers), and finally by returning to deter flower-feeding beetles and seed predators. Therefore, if ant abundance per branch is consistent over the flowering and fruiting

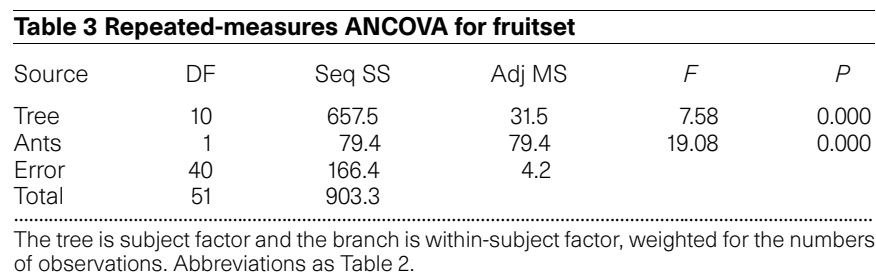

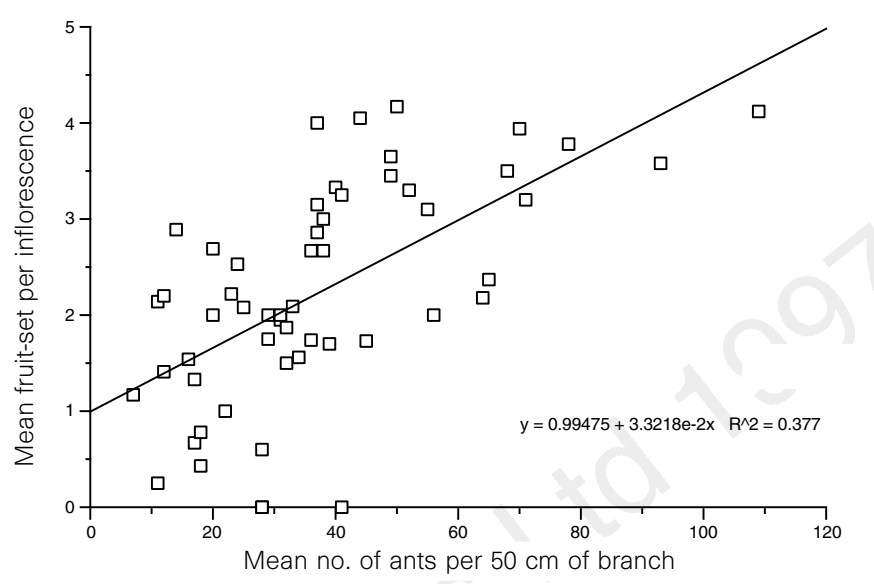

Figure 3 Effects of ant-guard abundance on seed-set. Ant abundance is the number per branch for 5 branches on each of 11 trees; seed-set was scored on the same branch lengths. The line shown is the best-fit linear regression.

period, it should be positively related to eventual seed-set on a given branch. Counts of ants per branch on 10 branches from a single tree over 4 days show a highly significant rank effect of branch (Friedman, $P=0.006$ ), indicating that each branch has a rather fixed number of patrollers over time (as expected, given the presence of pseudogalls of fixed size and number). To show the effects of ant activities on overall pollination and seed-set, we therefore compared five branches from each of eleven A. zanzibarica trees (Fig. 3). The mean ant abundance per branch is positively correlated with the mean fruit-set per inflorescence for each of the 11 trees. Using a repeated measure ANCOVA (Table 3) with 'trees' as units and 'branches' as repeats, the relationship between ant activity and fruitset is highly significant $(P=0.000)$. None of the other 'non-ant' factors measured (see Methods) is a significant predictor of fruitset. Nor are there likely to be environmental factors differing between the 11 adjacent trees that could independently affect both ant abundance and fruit-set ${ }^{5,6}$. Therefore the presence of guarding ants per se can be taken to assist fruit-set in this Acacia species.

\section{Methods}

All studies were carried out on Acacia trees in the western end of Mkomazi Game Reserve, Northern Tanzania. Flower visiting was scored by quiet continuous observation of tagged $0.6-\mathrm{m}$ branch lengths, with individual flowers noted and aged. To assess the consistency of ant activity patterns, patrolling ants were scored at different times of day over 4 days (on 22, 24, 27 and 28 November 1995) on ten 0.5-m tagged lengths of branch on one tree.

At about 07:00 on two days, we set up and tagged flowers, treated in the following categories: untouched young flowers; untouched old flowers; young flowers 'wiped' onto old flowers; old flowers 'wiped' onto old flowers, as a control for handling effects. Wiping involved smearing the recipient flower's surfaces with either a young or an old flower from the same tree; the picked 'donor' flower, held in forceps, was moved three times over the recipient flower to give contact with most of the spherical exposed surface of massed anthers and stigmas.

To assess ant effects on fruit-set, we selected eleven A. zanzibarica trees, all growing close together in a small stand on flat ground to reduce edaphic variations, and tagged equal $0.5-\mathrm{m}$ lengths of five branches on each tree. We then scored ant abundance on each branch totalled across 12 sampling times (07:30-14:30) on 2 December 1995. Numbers and sizes of pseudogalls on that branch were also scored, together with numbers of flowers of each age, the height, aspect and shading of branch, and the tree size (height and trunk girth), to rule out other possible causes of variation in seed-set. Finally, we counted all seeds on each former flower-head site separately (range, 0-11 per flower site, with 0-39 sites per branch). 
1. Janzen, D. H. Coevolution of mutualism between ants and Acacia in Central America. Evolution 20, 249-275 (1966).

2. Hocking, B. Insect associations with the swollen-thorn acacias. Trans. R. Ent. Soc. Lond. 122, 211-255. 3. Knox, R. B., Marginson, R., Kenrick, J. \& Beattie, A. J. in Insects and the Plant Surface (eds Juniper, B. E. \& Southwood, T. R. E.) 295-307 (Arnold, London, 1986).

4. Del-Claro, K., Berto, V. \& Reu, W. Effect of herbivore deterrence by ants on the fruit set of an extrafloral nectary plant Qualea multiflora (Vochysiaceae). J. Trop. Ecol. 12, 887-792 (1996).

5. Niesenbaum, R. A. Linking herbivory and pollination: defoliation and selective fruit abortion in Lindera benzoin. Ecology 77, 2324-2331 (1996).

6. Koptur, S. in Insect-Plant Interactions (ed. Bernays, E.) 81-129 (CRC Press, Boca Raton, 1992).

7. Ross, J. H. An analysis of the African Acacia species: their distribution, possible origins and relationships. Bothalia 13, 389-413 (1981).

8. Young, T. P., Stubblefield, C. H. \& Isbell, L. A. Ants on swollen thorn Acacias: species coexistence in a simple system. Oecologia 109, 98-107 (1997).

9. Stone, G. N., Willmer, P. G. \& Nee, S. Daily partitioning of pollinators in an African Acacia community. Proc. R. Soc. Lond. B 263, 1389-1393 (1996).

10. Tybirk, K. Pollination, breeding system and seed abortion in some African acacias. Bot. J. Linn. Soc 112, 107-137 (1993)

11. Feinsinger, P. \& Swarm, L. A. How common are ant-repellent nectars? Biotropica 10, 238-139 (1978) 12. Prys-Jones, O. E. \& Willmer, P. G. The biology of alkaline nectar in the Purple Toothwort (Lathrea clandestina): ground level defence. Biol. J. Linn. Soc. 45, 373-388 (1992).

Acknowledgements. We thank D. Mafunde at Mkomazi Research Station for expert field assistance; T. Morgan and N. McWilliam for invaluable logistic back-up; and M. Ritchie and J. Graves for statistical advice. We thank the Royal Geographical Society, the Darwin Initiative and the British Council for financial support, as part of the Mkomazi Ecological Research Programme, and the Department of Wildlife of the Tanzanian Government.

\section{Evolution of genetic} redundancy

\section{Martin A. Nowak*, Maarten C. Boerlijst*, Jonathan Cooke $\nmid$ \& John Maynard Smith}

* Department of Zoology, University of Oxford, South Parks Road, Oxford OX1 3PS, UK

$\dagger$ National Institute for Medical Research, The Ridgeway, London NW7 1AA, UK $\ddagger$ School of Biological Sciences, University of Sussex, Brighton BN1 9QG, UK

Genetic redundancy means that two or more genes are performing the same function and that inactivation of one of these genes has little or no effect on the biological phenotype. Redundancy seems to be widespread in genomes of higher organisms ${ }^{1-9}$. Examples of apparently redundant genes come from numerous studies of developmental biology ${ }^{10-15}$, immunology $y^{16,17}$, neurobiology $y^{18,19}$ and the cell cycle $^{20,21}$. Yet there is a problem: genes encoding functional proteins must be under selection pressure. If a gene was truly redundant then it would not be protected against the accumulation of deleterious mutations. A widespread view is therefore that such redundancy cannot be evolutionarily stable. Here we develop a simple genetic model to analyse selection pressures acting on redundant genes. We present four cases that can explain why genetic redundancy is common. In three cases, redundancy is even evolutionarily stable. Our theory provides a framework for exploring the evolution of genetic organization.

There are an increasing number of observations demonstrating that experimental inactivation of certain genes has no apparent effect on the phenotype or fitness of an animal. In specific cases, it seems that the natural function of a gene can be taken over by another gene. Such a redundant genetic organization is sensible from an engineer's point of view: important functions require backup devices that can take over in case of failure. But can natural selection favour the emergence and stability of redundant genes?

Consider a population of animals in which some essential function can be performed by genes at either of two loci, $A$ and $B$. (We use the word 'function' to refer to an effect of a gene during development; thus two genes coding for different proteins can have the same function.) Non-functional alleles, $a$ and $b$, arise by mutation at rates $u_{a}$ and $u_{b}$ per generation; reverse mutations are ignored. For simplicity, we consider a haploid population, but the

\section{a}

Model 1

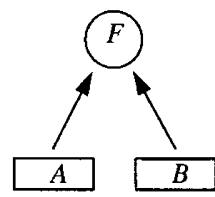

\begin{tabular}{|ll|}
\hline Gene & $F$ \\
$A$ & 1 \\
$a$ & 0 \\
$B$ & 1 \\
$b$ & 0 \\
\hline
\end{tabular}

\begin{tabular}{|ll|}
\hline Genotype & Fitness \\
$A B$ & 1 \\
$A b$ & 1 \\
$a B$ & 1 \\
$a b$ & 0 \\
\hline
\end{tabular}

b

Model 2

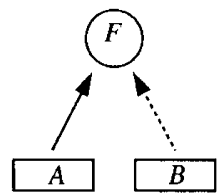

\begin{tabular}{|ll|}
\hline Gene & $F$ \\
$A$ & 1 \\
$a$ & 0 \\
$B$ & $h$ \\
$b$ & 0 \\
\hline
\end{tabular}

\begin{tabular}{|ll|}
\hline Genotype & Fitness \\
$A B$ & 1 \\
$A b$ & 1 \\
$a B$ & $h$ \\
$a b$ & 0 \\
\hline
\end{tabular}

C

Model 3

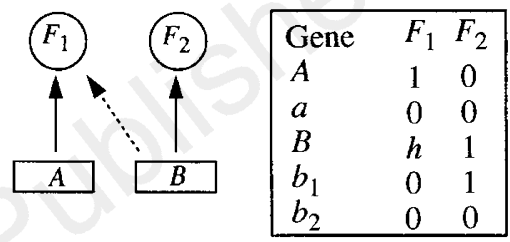

\begin{tabular}{|ll|}
\hline Genotype & Fitness \\
$A B$ & 1 \\
$A b_{1}$ & 1 \\
$a B$ & $h$ \\
other & 0 \\
\hline
\end{tabular}

Figure 1 Models of genetic redundancy. a, Model 1. If genes $A$ and $B$ perform function $F$ with equal efficacy, then redundancy does not persist. For unequal mutation rates, the gene with higher mutation rate will become extinct. b. Model 2. Redundancy can be evolutionarily stable if $B$ performs the function with lower efficacy, but also has a lower mutation rate. c, Model 3. Suppose $A$ and $B$ perform different functions, $F_{1}$ and $F_{2}$, but $B$ also performs function $F_{1}$, but with lower efficacy than gene $A$. The redundant organization for performing function $F_{1}$ is evolutionarily stable if the mutation rate that eliminates the cross-function in $B$ (but leaves its primary function unaffected) is lower than the mutation rate that inactivates $A$.

models can be extended to diploid populations and the conclusions remain essentially unchanged. There are four genotypes: $A B, A b, a B$ and $a b$. In each generation, random mating is followed by mutation and selection. Natural selection can maintain both genes if redundancy is only apparent, that is, if the $A B$ genotype is fitter than the other genotypes. Less obvious is the question of whether natural selection can maintain true redundancy in the sense that an individual with one of the two genes is as fit as an individual with both. Models 1-3 will address this question. Model 4 studies the consequence of developmental errors.

In model 1, we assume that both genes are equally effective, and that each can function perfectly on its own (Fig. 1a). The fitness of $A B, A b$ and $a B$ is one, while the fitness of $a b$ is zero. Let us first consider the case where the mutation rates in both genes are the same: $u_{a}=u_{b}=u$. The system admits a line of equilibria. All trajectories converge to this line. For small mutation rates, the maximum equilibrium frequency of $A B$ is approximately $1-2 \sqrt{ }(u / r)$, where $r$ is the recombination rate between the two loci. Thus a large proportion of individuals can carry functional alleles for both genes.

There is, however, an important caveat. We have assumed that the mutation rates $u_{a}$ and $u_{b}$ are equal. But any small deviation from $u_{a}=u_{b}$ destroys the equilibrium line. If $u_{a} \neq u_{b}$ then model 1 does not admit any interior equilibrium, and redundancy does not survive $^{22}$. A simple way of understanding this result is as follows. At equilibrium, the rate at which deleterious genes arise by mutation must equal the rate at which they are removed by selection. Because 